Check for updates

Cite this: RSC Adv., 2017, 7, 37105

Received 16th June 2017 Accepted 19th July 2017

DOI: 10.1039/c7ra06722d

rsc.li/rsc-advances

\title{
A ferrocene-based organogel with multi-stimuli properties and applications in naked-eye recognition of $\mathrm{F}^{-}$and $\mathrm{Al}^{3+} \uparrow$
}

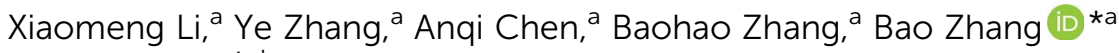 \\ and Jian Song *ab
}

A novel organogelator (F-6) with multiple hydroxyl groups and a ferrocene group was designed and synthesized. F-6/chloroform gel exhibited smart thixotropic property and displayed stimuli responsiveness to temperature, mechanical stress, redox, anions and cations. Further, a gel-sol phase transition was observed when halogen anions $\left(\mathrm{F}^{-}, \mathrm{Cl}^{-}, \mathrm{Br}^{-}\right)$were added. In particular, only the addition of $\mathrm{F}^{-}$converted the color of the gel from orange to red and was therefore unique for $\mathrm{F}^{-}$. More interestingly, $\mathrm{Al}^{3+}$ could also be recognized by the naked eye through the color change and gel-sol transition. The conclusive stoichiometric ratio between $\mathrm{F}-6$ and $\mathrm{Al}^{3+}$ was determined to be $2: 1$. The detection limit of $\mathrm{Al}^{3+}$ by using F-6 for the analysis was calculated to be $6.84 \times 10^{-7} \mathrm{M}$ in $\mathrm{CH}_{3} \mathrm{OH} / \mathrm{H}_{2} \mathrm{O}$ $(8: 2, \mathrm{v} / \mathrm{v})$ at room temperature, which is far below the World Health Organization's $(\mathrm{WHO})$ acceptable limit $\left(1.85 \mu \mathrm{M}\right.$ of $\left.\mathrm{Al}^{3+}\right)$. Thus, the recognition of $\mathrm{F}^{-}$and $\mathrm{Al}^{3+}$ was achieved through the $\mathrm{F}-6 /$ chloroform gel system, which was uncommon among organogels. It was shown that the ferrocene group played an important role in the response to ions.

\section{Introduction}

Supramolecular gels are a kind of soft material that are formed by the self-assembly of low-molecular-weight gelators (LMWGs) through weak intermolecular interactions, such as hydrogen bonding, van der waals interactions, $\pi-\pi$ stacking, electrostatic interactions, and so on. ${ }^{1-3}$ Due to the weak nature of noncovalent bonding, the reversible sol-gel transition can be realized when external stimuli are applied, such as ultrasound, light, $\mathrm{pH}$, mechanical stress, and ions. ${ }^{4-10}$ Thus, these stimuliresponsive gels show potential applications in biocatalysis, chemosensors, displays, drug delivery, etc. ${ }^{\mathbf{1 1 - 1 4}}$ Benefiting from the simple structure of low-molecular-weight gelators, functional groups can be introduced to form functionalized stimuliresponsive supramolecular gels. ${ }^{15-19}$ Significant progress in the formation of such smart soft materials has been made during the past few years. ${ }^{20-26}$ However, it is still a great challenge to design a high performance stimuli-responsive gel system with multiple functions.

Furthermore, the recognition of ions including cations and anions has been an attracting topic during the past few

${ }^{a}$ School of Chemical Engineering and Technology, Tianjin University, Tianjin, China. E-mail: baozhang@tju.edu.cn; songjian@tju.edu.cn

${ }^{b}$ The Co-Innovation Center of Chemistry, Chemical Engineering of Tianjin, Tianjin, China

$\uparrow$ Electronic supplementary information (ESI) available: Experimental details, additional images and figures. See DOI: 10.1039/c7ra06722d years. ${ }^{27-35}$ 'Naked eye' recognition is the most convenient way to identify an ion, such as the change of color and state. Due to the visual transition of gel-sol process, gel systems provide an efficient platform for ion recognition. ${ }^{36}$

In order to construct a multi-function responsive gel system, we designed two novel series of compounds ( $F_{n}$ and $A_{n}$, Scheme 1$)$ by connecting the ferrocene group to a polyol amide moiety via six ( $n$ $=6)$ or $0(n=0)$ methylene units. The multiple hydroxyl and the secondary amide groups were capable of forming hydrogen bonding intermolecularly ${ }^{37-39}$ and the ferrocene group was introduced as a redox center. Interestingly, it was found that only F-6 could form gel in common solvents like chloroform, benzene, etc., which indicated that the presence of the aromatic acetal and the length of alkyl linkage between the polyol amide moiety and ferrocene unit had a profound effect on the gelation abilities of these compounds. More interestingly, F-6/chloroform gel exhibited smart thixotropic property and displayed stimuli responsiveness to temperature, mechanical stress, redox, anions and cations. The process of gel-sol phase transition was observed when
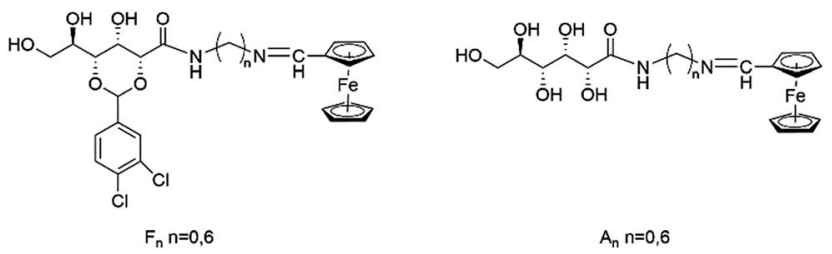

Scheme 1 Molecular structure of compound $F_{n}$ and $A_{n}$. 
halogen anions $\left(\mathrm{F}^{-}, \mathrm{Cl}^{-}, \mathrm{Br}^{-}\right)$were added. In particular, only the addition of $\mathrm{F}^{-}$converted the color of the gel from orange to red which was unique. Further, $\mathrm{Al}^{3+}$ could also be recognized by naked eye through the color change and gel-sol transition. The detection limit of $\mathrm{Al}^{3+}$ by using F-6 for the analysis was calculated to be 6.84 $\times 10^{-7} \mathrm{M}$ in $\mathrm{CH}_{3} \mathrm{OH} / \mathrm{H}_{2} \mathrm{O}(8: 2)$ at room temperature, which is far below the World Health Organization (WHO) acceptable limit $\left(1.85 \mu \mathrm{M}\right.$ of $\left.\mathrm{Al}^{3+}\right)$. Thus, the recognition of $\mathrm{F}^{-}$and $\mathrm{Al}^{3+}$ was achieved through the F-6/chloroform gel system, which was uncommon among organogels.

\section{Experimental}

\subsection{Materials and methods}

Materials. All chemicals were purchased and used without further purification.

Nuclear magnetic resonance (NMR) spectrum. ${ }^{1} \mathrm{H}$ and ${ }^{13} \mathrm{C}$ NMR data were collected on a Bruker AVANCE III $400 \mathrm{MHz}$ spectrometer $\left({ }^{1} \mathrm{H}: 400 \mathrm{MHz} ;{ }^{13} \mathrm{C}: 100 \mathrm{MHz}\right)$.

Mass spectra. Mass spectra were recorded using a TOF-QII high resolution mass spectrometer and an Autoflex tof/tofIII MALDI/TOF mass spectrometer.

UV-vis spectroscopy. The UV-Vis spectroscopic studies were measured at room temperature using a UV-1800 spectrometer.

Scanning electron microscopy (SEM). SEM measurements were carried out using a Hitachi S-4800 SEM. Samples were prepared and dried under the ambient conditions for two weeks.

Gelation. The weighed amount of F- 6 gelator was added into the measured volume of solvent in the tube and heated until the solid was dissolved, after which the solution was allowed to cool to room temperature. A "stable to inversion test tube method" was adopted.

Rheological study. The rheological measurements were carried out using a MCR301 rheometer equipped with stainless coaxial cylinder rheometer (cup diameter, $16 \mathrm{~mm}$; bob diameter, $15 \mathrm{~mm}$ ). Experiments were performed with gels at the concentration of $2 \%(\mathrm{w} / \mathrm{v})$ under the room temperature of $20^{\circ} \mathrm{C}$.

Calculation of the detection limit. The detection limit (DL) of F- 6 for $\mathrm{Al}^{3+}$ was determined using the equation: $\mathrm{DL}=K \times \mathrm{Sb} / S$, where $K=2$ or 3 (we take 3 in this case), Sb is the standard deviation of the blank solution and $S$ is the slope of the calibration curve. ${ }^{35}$

\subsection{Synthesis of compounds}

The compounds were synthesized through conventional reactions. F- 6 was characterized by ${ }^{1} \mathrm{H}$ NMR, ${ }^{13} \mathrm{C}$ NMR, and ESI-MS. The details of the synthesis and characteristics are described in the ESI. $\uparrow$

\section{Results and discussion}

\subsection{Gelation behavior of $F_{n}$ and $A_{n}$}

The gelation abilities of $F_{n}$ and $A_{n}$ were tested in 14 different solvents with the concentration of $2 \mathrm{wt} \%(\mathrm{w} / \mathrm{v})$. The results were summarized in Table S1 (ESI $\dagger$ ). It was found that only F-6 could gel some solvents via a heating-cooling process which indicated that both the aromatic acetal and a certain length of alkyl linkage between the polyol amide moiety and ferrocene unit were required for the gel formations for this ferrocene-polyol amide type compound. It was also found that F-6 could gel 1octanol but dissolved in alcohols with a short alkyl chain such as methanol. Chloroform and aromatic solvents such as dichlorobenzene and toluene could also be gelled. Interestingly, the critical gelation concentration (CGC) value of F-6 for gelling dichlorobenzene was only $0.09 \mathrm{wt} \%$, which fell into the category of "super-gelator".

The F-6/chloroform gel turned into solution upon heating up to $50{ }^{\circ} \mathrm{C}$, and resting the solution for 5 minutes at room temperature resulted in the formation of gel again. In addition, F-6 could form stable gel in chloroform when the $\mathrm{pH}$ value of the system was in the range of 4-9. When the $\mathrm{pH}$ value of the system was smaller than 4 or greater than 9 , orange solution was obtained.

The morphologies of F-6/chloroform xerogel were characterized using SEM. Cross-linked nanofibrillar network morphology was observed so that a lot of solvent could be entrapped (Fig. 1). The width of nanofibrillar network in xerogel formed from F-6 was about $0.25-0.45 \mu \mathrm{m}$.

\subsection{Rheological study}

It was found that the gel-sol phase transition could be observed by stirring F-6/chloroform gel and the gel was reproduced by resting the solution for 10 minutes at room temperature. Thus, rheological measurements were performed to further study this reversible sol-gel phase transition process. Oscillatory rheological results of F-6/chloroform gel ( $2 \mathrm{wt} \%$, w/v) was shown in Fig. S6(a) (ESI $\dagger$ ). In a dynamic strain sweep measurement in which the frequency was $1 \mathrm{~Hz}$, the values of the storage modulus $\left(G^{\prime}\right)$ and the loss modulus $\left(G^{\prime \prime}\right)$ exhibited a weak correlation from $0.01 \%$ to $0.5 \%$ with strain $\left(G^{\prime}>G^{\prime \prime}\right)$, indicating the F-6/ chloroform sample was gel. A sharp deviation from linearity of both modulus were observed with increasing strain gradually. When about $7 \%$ of strain was applied to the gel, the value of $G^{\prime}$ was beginning to be smaller than that of $G^{\prime \prime}$, indicating the mechanical breakup of the gel.

Next, the thixotropic properties of the gel was studied. The sample was sheared at a constant strain of $100 \%$ and the frequency kept at $1 \mathrm{~Hz}$ during the measurement. The evolution of both $G^{\prime}$ and $G^{\prime \prime}$ as a function of time was then obtained as
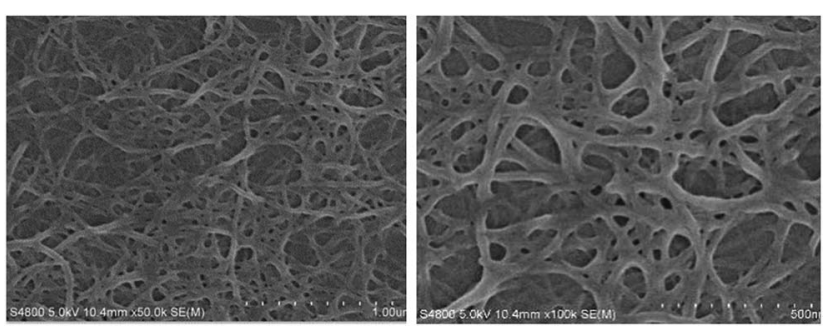

Fig. 1 SEM images of the xerogels formed from compound F-6 in chloroform. 
shown in Fig. S6(b). $\uparrow$ It was found that the gel was partially recovered after removing the stimulus.

\subsection{Chemical oxidation}

It is known that the ferrocenyl group is easy to be oxidized both chemically and electronically. It was found that in the presence of one mole equivalent of $\left[\mathrm{Ce}\left(\mathrm{NH}_{4}\right)_{2}\left(\mathrm{NO}_{3}\right)_{6}\right]$ (CAN) dissolved in $\mathrm{H}_{2} \mathrm{O}(0.1 \mathrm{~mL})$, the $\mathrm{F}-6 /$ chloroform gel gradually turned into a dark green solution (Fig. 2a). The phase transition was believed to be induced by chemical oxidation of the ferrocenyl moiety, which was confirmed by parallel experiments. When $\mathrm{NH}_{4} \mathrm{NO}_{3}$ and $\left[\mathrm{Ce}\left(\mathrm{NO}_{3}\right)_{3}\right]$ were used instead of $\left[\mathrm{Ce}\left(\mathrm{NH}_{4}\right)_{2}\left(\mathrm{NO}_{3}\right)_{6}\right]$ and no change was observed during the process. Further evidence was obtained by the comparison of the UV-Vis absorptions of F-6/ chloroform gel and the resultant oxidized sample. It was found that the absorption at $454 \mathrm{~nm}$ corresponding to the ferrocenyl moiety disappeared and a new absorption at $625 \mathrm{~nm}$ was observed, which indicated the oxidation of ferrocenyl group (Fig. 2b). ${ }^{8}$

Furthermore, when the ferrocene group in F-6 was replaced by a salicylaldehyde moiety, the gelator S-6 was obtained (Scheme S6, ESI $\dagger$ ). S-6/chloroform gel was also tested under the same conditions. However there was no change with the group of salicylaldehyde, which indicated the importance of ferrocene on the response to chemical oxidation (see the details in ESI $\dagger$ ).

\subsection{Anion recognition}

Considering the multiple hydroxyl groups and the amide unit present in F-6 were capable of forming intermolecular hydrogen bonding, the interaction of F-6 with anions was investigated. One mole equivalent of anions as tetra-butyl ammonium salts $\left(\mathrm{F}^{-}, \mathrm{Cl}^{-}, \mathrm{Br}^{-}, \mathrm{I}^{-}, \mathrm{NO}_{3}{ }^{-}, \mathrm{PO}_{4}{ }^{3-}, \mathrm{SO}_{4}{ }^{2-}\right)$ dissolved in methanol $(0.1 \mathrm{~mL})$ was carefully placed to the surface of the F-6/ chloroform gel. Interestingly, the gel turned into a red solution within 3 minutes when $\mathrm{F}^{-}$was added. Upon addition of other halogen anions such as $\mathrm{Cl}^{-}$and $\mathrm{Br}^{-}$, the gel slowly turned into a solution in 20 minutes and 12 hours, respectively. Only a very small part of the gel was disrupted even after 72 hours with the addition of $\mathrm{I}^{-}$. While F-6/chloroform gel could not be destroyed with other anions $\left(\mathrm{NO}_{3}{ }^{-}, \mathrm{PO}_{4}{ }^{3-}, \mathrm{SO}_{4}{ }^{2-}\right)$. Further, it was shown that the addition of a small amount of methanol had

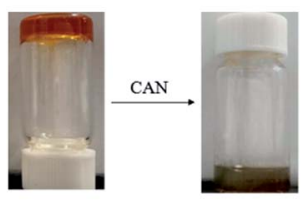

(a)

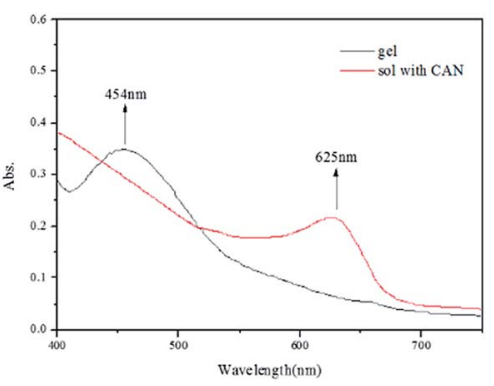

(b)
Fig. 2 (a) Sol-gel phase transition of F-6/chloroform gel triggered by chemical oxidation (b) UV/Vis spectra of F-6 in presence and absence of CAN. no influence on the gel, which ruled out the interference of solvent. More interestingly, only the addition of $\mathrm{F}^{-}$converted the color of the system from orange to red which was unique for $\mathrm{F}^{-}$among all the four halogen anions examined. The red solution with $\mathrm{F}^{-}$could be converted back to orange by the addition of aqueous ammonia (Fig. 3).

UV/Vis spectroscopy in methanol was taken to investigate the interaction between F-6 and anions. The changes in the UV/Vis absorption spectra of F-6 with the addition of anions were shown in Fig. 4. The UV/Vis spectrum of F-6 $\left(10^{-4} \mathrm{M}\right)$ in methanol solution showed two absorption peaks at about $270 \mathrm{~nm}$ and $325 \mathrm{~nm}$, corresponding to $\pi \rightarrow \pi^{*}$ transition of ferrocene unit and the group of $\mathrm{C}=\mathrm{N}$ under the condition. However, there was only one wide absorption peak at about $325 \mathrm{~nm}$ with the addition of $\mathrm{F}^{-}$, which might be caused by the red shift of the absorption at $270 \mathrm{~nm}$ and the combination with that at $325 \mathrm{~nm}$. Only the absorption of the liquid with $\mathrm{F}^{-}$added was different from the blank sample, while it was almost unchanged with other anions. With the addition of ammonia to the system containing $\mathrm{F}^{-}$, the absorption spectra changed back to that of the blank sample. The results of UV/Vis spectra showed that $\mathrm{F}^{-}$might form the hydrogen bonding with Schiff base proton which resulted in the color change.

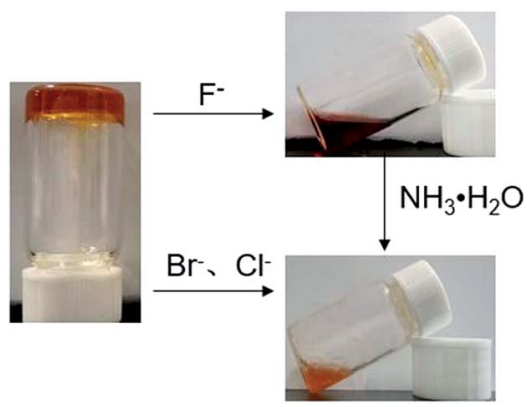

Fig. 3 Photographs of F-6/chloroform gel upon the addition of TBA$\mathrm{F}, \mathrm{TBA}-\mathrm{Cl}$, TBA-Br.

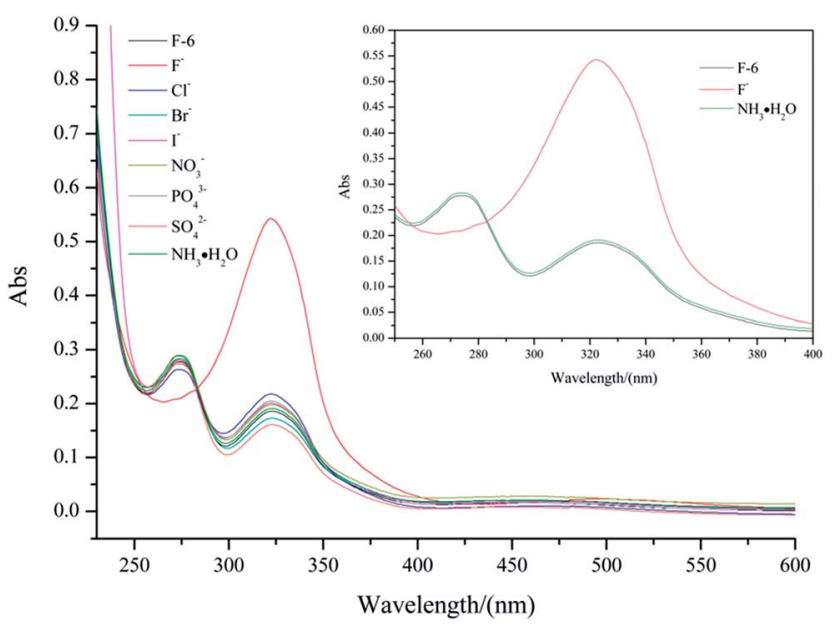

Fig. 4 UV-vis spectra of F- 6 with addition of different anions as tetrabutyl ammonium salts in methanol. 
${ }^{1} \mathrm{H}$ NMR was conducted to investigate the interaction of anions with F-6. When 2 equivalents of $\mathrm{F}^{-}, \mathrm{Cl}^{-}$or $\mathrm{Br}^{-}$were added to F-6/chloroform gel, the resonance of amide proton (NH) was shifted downfield to $7.611,7.613$ or 7.615 ppm from $7.600 \mathrm{ppm}$, respectively. Thus, it is believed that the addition of halogen anions $\left(\mathrm{X}^{-}\right)$destroyed the original hydrogen bonding and resulted in the formation of $\mathrm{X} \cdots \mathrm{HNCO}$ hydrogen bonding. Furthermore, an obvious shift of the resonance of Schiff base proton $(-\mathrm{CH}=\mathrm{N}-)$ from $8.068 \mathrm{ppm}$ to $8.076 \mathrm{ppm}$ was observed for the sample containing $\mathrm{F}^{-}$, and no such shift obtained for those $\mathrm{Cl}^{-}$and $\mathrm{Br}^{-}$samples (Fig. 5a).

To further investigate the interaction between $\mathrm{F}^{-}$and F-6, ${ }^{1} \mathrm{H}$ NMR of the F-6/chloroform gel with different amount of $\mathrm{F}^{-}$ added was conducted (Fig. 5b). Interestingly, it was found that when one mole equivalent of $\mathrm{F}^{-}$were added to $\mathrm{F}-6 /$ chloroform gel, the resonance of Schiff base proton was shifted downfield from $8.068 \mathrm{ppm}$ to $8.074 \mathrm{ppm}$, and the resonance of amide proton was unchanged. With the continuous addition of $\mathrm{F}^{-}$, the resonances of $-\mathrm{CH}=\mathrm{N}$ - and $-\mathrm{NH}$ - protons were shifted downfield to 8.076 and $7.611 \mathrm{ppm}$, respectively. After adding 4 mole equivalent of $\mathrm{F}^{-}$, the resonance at $8.068 \mathrm{ppm}$ corresponding to the Schiff base proton disappeared and the resonance of - $\mathrm{NH}-$ proton was shifted further downfield to $7.621 \mathrm{ppm}$. It indicated that $\mathrm{F}^{-}$preferentially formed hydrogen bonding with Schiff base proton which caused the color change from orange to red. Excess $\mathrm{F}^{-}$interacted with the proton of amide to form $\mathrm{F}^{-} \ldots$ HNCO hydrogen bonding. The MALDI/TOF mass spectrum of complexes $\left(\mathrm{F}-6-\mathrm{F}^{-}\right)$was shown in Fig. S7 (ESI $\dagger$ ). After adding one mole equivalent of ammonia, the resonance of $-\mathrm{CH}=\mathrm{N}-$ proton was shifted up-field back to $8.070 \mathrm{ppm}$ which indicated the stronger interaction between ammonia and $\mathrm{F}^{-}$compared to that between Schiff base and $\mathrm{F}^{-}$.

(a)

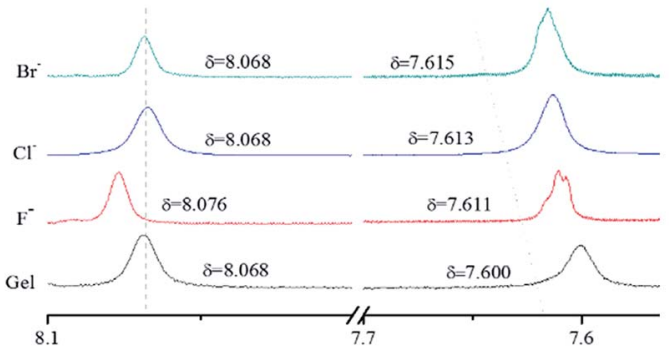

(b)

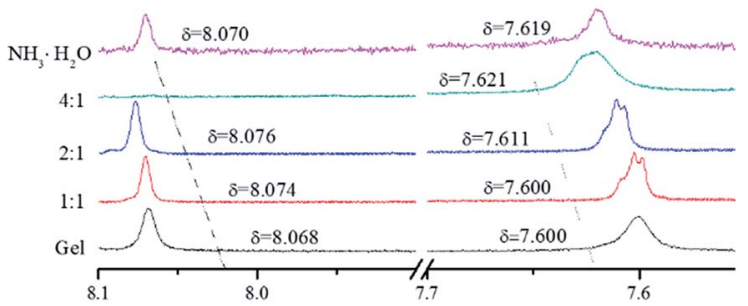

Fig. $5{ }^{1} \mathrm{H}$ NMR spectra of (a) F-6 in chloroform with different anions and (b) F-6 with different concentrations of $\mathrm{F}^{-}$.
S-6/chloroform gel was tested under the same conditions. UV/Vis spectroscopy and ${ }^{1} \mathrm{H}$ NMR of S-6 with different anions was also conducted. The details were described in the ESI (Fig. S8-S9†).

\subsection{Detection of $\mathrm{Al}^{3+}$}

The response of F-6/chloroform gel to metal ions was also investigated. One mole equivalent of metallic ion $\left(\mathrm{Na}^{+}, \mathrm{K}^{+}\right.$, $\mathrm{Ba}^{2+}, \mathrm{Mg}^{2+}, \mathrm{Ca}^{2+}, \mathrm{Al}^{3+}, \mathrm{Fe}^{3+}, \mathrm{Cu}^{2+}, \mathrm{Pb}^{2+}, \mathrm{Zn}^{2+}, \mathrm{Cd}^{2+}, \mathrm{Ni}^{2+}, \mathrm{Co}^{2+}$, $\left.\mathrm{Mn}^{2+}\right)$ as nitrate salts dissolved in methanol $(0.1 \mathrm{~mL})$ was carefully placed to the surface of the F-6/chloroform gel. It was found that when $\mathrm{Al}^{3+}, \mathrm{Fe}^{3+}, \mathrm{Cu}^{2+}, \mathrm{Pb}^{2+}$ or $\mathrm{Zn}^{2+}$ was added, the gel gradually turned into solution with the color changing from orange to dark red. Neither the phase transition nor the color change was observed with the other metal ions added. More interestingly, the gel converted into solution completely in only $20 \mathrm{~min}$ by introducing $\mathrm{Al}^{3+}$, and more than 3 hours were required with the addition of the other four metal ions. Therefore, the fast recognition of $\mathrm{Al}^{3+}$ could be realized. Furthermore, the dark red solution reformed the orange gel upon the addition of one equivalent of EDTA-2Na dissolved in $\mathrm{H}_{2} \mathrm{O}(0.1 \mathrm{~mL})$ (Fig. 6).

The metal binding interaction with the ligand F-6 was further carried out for various metallic ions as nitrate salts $\left(\mathrm{Na}^{+}\right.$, $\mathrm{K}^{+}, \mathrm{Ba}^{2+}, \mathrm{Mg}^{2+}, \mathrm{Ca}^{2+}, \mathrm{Al}^{3+}, \mathrm{Fe}^{3+}, \mathrm{Cu}^{2+}, \mathrm{Pb}^{2+}, \mathrm{Zn}^{2+}, \mathrm{Cd}^{2+}, \mathrm{Ni}^{2+}, \mathrm{Co}^{2+}$, $\left.\mathrm{Mn}^{2+}\right)$ in methanol/ $\mathrm{H}_{2} \mathrm{O}(8: 2, \mathrm{v} / \mathrm{v})$. It was seen that the color of the liquid turned into pink as soon as $\mathrm{Al}^{3+}, \mathrm{Fe}^{3+}, \mathrm{Cu}^{2+}, \mathrm{Pb}^{2+}, \mathrm{Zn}^{2+}$ was added, while the color was unchanged with the other metal ions (Fig. 7). The UV/Vis spectrum of F-6 $\left(10^{-5} \mathrm{M}\right)$ in methanol/ $\mathrm{H}_{2} \mathrm{O}(8: 2)$ solution showed an absorption at about $300 \mathrm{~nm}$, which is characteristic for the presence ferrocene unit under the condition (Fig. S10, ESI $\dagger$ ). Upon the addition of cations $\left(\mathrm{Al}^{3+}\right.$, $\left.\mathrm{Fe}^{3+}, \mathrm{Cu}^{2+}, \mathrm{Pb}^{2+}, \mathrm{Zn}^{2+}\right)$, a significant red shift at about $320 \mathrm{~nm}$ was observed. The absorbance with $\mathrm{Al}^{3+}$ was the biggest. Thus, the interaction of F- 6 with $\mathrm{Al}^{3+}$ was further studied in methanol/ $\mathrm{H}_{2} \mathrm{O}(8: 2)$.

Titration experiment of $\mathrm{Al}^{3+}$ was conducted. With incrementally added amounts of $\mathrm{Al}^{3+}(0-90 \mu \mathrm{M})$, the absorption band at $320 \mathrm{~nm}$ progressively increased, so that the sensitivity of F-6 towards $\mathrm{Al}^{3+}$ was clear (Fig. S11, ESI $\dagger$ ). The conclusive stoichiometric ratio between $\mathrm{F}-6$ and $\mathrm{Al}^{3+}$ was determined to be $2: 1$ by using the method of Job's plot (Fig. S12, ESI $\dagger$ ). To further confirm the stoichiometry between F-6 and $\mathrm{Al}^{3+}$, MALDI/TOF-

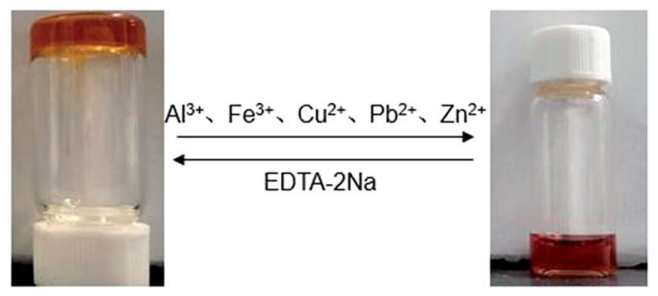

Fig. 6 Reversible sol-gel phase transition of F-6/chloroform gel triggered by the addition of metal ions and followed by the addition of EDTA-2Na. 


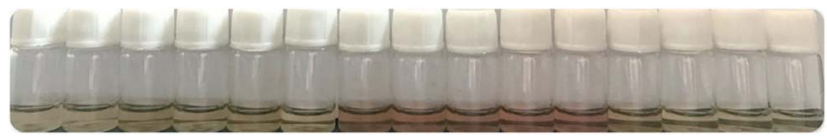

Fig. 7 Photographs of $\mathrm{F}-6$ in methanol/ $\mathrm{H}_{2} \mathrm{O}(8: 2)$ solution and followed by the addition of metal ions (from left to right: blank sample, $\mathrm{Na}^{+}, \mathrm{K}^{+}, \mathrm{Ba}^{2+}, \mathrm{Mg}^{2+}, \mathrm{Ca}^{2+}, \mathrm{Al}^{3+}, \mathrm{Fe}^{3+}, \mathrm{Cu}^{2+}, \mathrm{Pb}^{2+}, \mathrm{Zn}^{2+}, \mathrm{Cd}^{2+}, \mathrm{Ni}^{2+}$, $\left.\mathrm{Co}^{2+}, \mathrm{Mn}^{2+}\right)$.

MS analysis was conducted. A mass peak at $\mathrm{m} / \mathrm{z} 1321.1$ was observed corresponding to $\left[(\mathrm{F}-6)_{2}-\mathrm{Al}^{3+}+1\right]^{+}$(Fig. S15, ESI $\dagger$ ).

The binding constant of complexation was calculated from the increasing absorption intensity at $320 \mathrm{~nm}$ by plotting $\alpha^{2} /(1$ $-\alpha) v s$. $\left[\mathrm{Al}^{3+}\right]^{-1}$ with linear fitting (Fig. S13, ESI†). The association constant of F-6 with $\mathrm{Al}^{3+}$ was $4.18 \times 10^{4} \mathrm{M}^{-2}$, indicating strong binding of F-6 with $\mathrm{Al}^{3+}$ at $2: 1$ stoichiometry. The detection limit of F- 6 for $\mathrm{Al}^{3+}$ was calculated to be $6.84 \times 10^{-7} \mathrm{M}$ by plotting the absorbance as a function of concentration of complex (F-6 plus $\mathrm{Al}^{3+}$ ), which is far below the WHO acceptable limit $\left(1.85 \mu \mathrm{M}\right.$ of $\left.\mathrm{Al}^{3+}\right) .{ }^{35}$ The calibration curve was shown in Fig. S14 (ESI†).

${ }^{1} \mathrm{H}$ NMR titration experiments had been carried out to investigate the interaction of $\mathrm{F}-6$ and $\mathrm{Al}^{3+}$ in chloroform (Fig. S16, ESI $\dagger$ ). Before the addition of $\mathrm{Al}^{3+}$, the resonance at $8.068 \mathrm{ppm}$ was attributed to the Schiff-base proton. After adding one mole equivalent of $\mathrm{Al}^{3+}$, the resonance was shifted downfield to $8.087 \mathrm{ppm}$, which indicated the coordination of $\mathrm{Al}^{3+}$ with the nitrogen atom of the Schiff base. The - $\mathrm{CONH}$ - proton at $7.600 \mathrm{ppm}$ was shifted downfield to $7.652 \mathrm{ppm}$ indicating the coordination of $\mathrm{Al}^{3+}$ with oxygen atom of amide group. The $-\mathrm{OH}$ proton at $4.805 \mathrm{ppm}$ was shifted to $4.839 \mathrm{ppm}$ indicating the coordination of $\mathrm{Al}^{3+}$ with oxygen atom of hydroxyl group. From the ${ }^{1} \mathrm{H}$ NMR analysis, it could be concluded that $\mathrm{Al}^{3+}$ interacted with F-6 molecules through the nitrogen atom of the Schiff base, and the oxygen atoms in the amide and hydroxyl groups. Interestingly, the resonances were shifted up-field back with the addition of EDTA-2Na corresponding to the recovery of the gel. Based on above experimental results, thus the proposed complex structure of F-6 with $\mathrm{Al}^{3+}$ is shown in Scheme 2.

S-6/chloroform gel was also tested under the same conditions. The details were described in the ESI (Fig. S17-S21†).

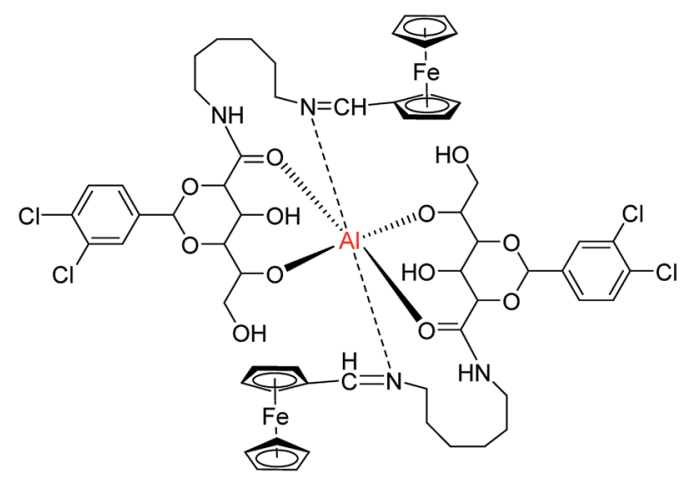

Scheme 2 Proposed structure of F-6 with $\mathrm{Al}($ (II) complex.

\section{Conclusions}

In summary, we fabricated a novel organogelator F-6 with multiple hydroxyl groups providing hydrogen bonding sites and a ferrocene group as redox center. F-6/chloroform gel exhibited smart thixotropic property and displayed stimuli responsiveness to temperature, mechanical stress, redox, anions and cations. Further, the process of gel-sol phase transition was observed when halogen anions $\left(\mathrm{F}^{-}, \mathrm{Cl}^{-}, \mathrm{Br}^{-}\right)$were added. In particular, only the addition of $\mathrm{F}^{-}$converted the color of the gel from orange to red which was unique for $\mathrm{F}^{-}$. The ${ }^{1} \mathrm{H}$ NMR results indicated that $\mathrm{F}^{-}$preferentially formed hydrogen bonding with Schiff base proton and then formed $\mathrm{F}^{-} \ldots \mathrm{HNCO}$ hydrogen bonding. More interestingly, $\mathrm{Al}^{3+}$ could also be recognized by naked eye through the color and state. The reversible gel-sol phase transition was realized when $\mathrm{Al}^{3+}$ was applied. The detection limit of F-6 for the analysis of $\mathrm{Al}^{3+}$ was calculated to be $6.84 \times 10^{-7} \mathrm{M}$ at room temperature, which is far below the WHO acceptable limit $\left(1.85 \mu \mathrm{M}\right.$ of $\left.\mathrm{Al}^{3+}\right)$. Thus, the recognition of $\mathrm{F}^{-}$and $\mathrm{Al}^{3+}$ was achieved through the $\mathrm{F}-6 /$ chloroform gel system, which was uncommon among organogels.

\section{Acknowledgements}

We are grateful that the National Natural Science Foundation of China $(21276188,21476164)$ offered the financial support.

\section{References}

1 R. G. Weiss, The past, present, and future of molecular gels. What is the status of the field, and where is it going, J. Am. Chem. Soc., 2014, 136, 7519-7530.

2 J. Zhang and C.-Y. Su, Metal-organic gels: from discrete metallogelators to coordination polymers, Coord. Chem. Rev., 2013, 257, 1373-1408.

3 G. Yu, X. Yan, C. Han and F. Huang, Characterization of supramolecular gels, Chem. Soc. Rev., 2013, 42, 6697-6722.

4 C. Pappas, T. Mutasa and P. J. Frederix, Transient supramolecular reconfiguration of peptide nanostructures using ultra-sound, Mater. Horiz., 2015, 2, 198-202.

5 P. Xing, X. Chu, M. Ma, S. Li and A. Hao, Supramolecular gel from folic acid with multiple responsiveness, rapid selfrecovery and orthogonal self-assemblies, Phys. Chem. Chem. Phys., 2014, 16, 8346-8359.

6 Y. Wang, P. Xing, S. Li, M. Ma, M. Yang, Y. Zhang, B. Wang and A. Hao, Facile stimuli-responsive transformation of vesicle to nanofiber to supramolecular gel via $\omega$-amino acid-based dynamic covalent chemistry, Langmuir, 2016, 32, 10705-10711.

7 P. Duan, N. Yanai, H. Nagatomi and N. Kimizuka, Photon upconversion in supramolecular gel matrixes: spontaneous accumulation of light-harvesting donor-acceptor arrays in nanofibers and acquired air stability, J. Am. Chem. Soc., 2015, 137, 1887-1894.

8 J. Yan, J. Liu, H. Lei, Y. Kang, C. Zhao and Y. Fang, Ferrocenecontaining thixotropic molecular gels: creation and a novel strategy for water purification, J. Colloid Interface Sci., 2015, 448, 374-379. 
9 L. Geng, Y. Li, Z. Wang, Y. Wang, G. Feng, X. Pang and X. Yu, Selective and visual $\mathrm{Ca}^{2+}$ ion recognition in solution and in a self-assembly organogel of the terpyridine-based derivative triggered by ultrasound, Soft Matter, 2015, 11, 8100-8104.

10 P. Xing, X. Chu, G. Du, M. Ma, S. Li and A. Hao, Utilizing dual responsive supramolecular gel to stabilize graphene oxide in apolar solvents, Colloid Polym. Sci., 2014, 292, 3223-3231.

11 Z. Yang, G. Liang and B. Xu, Enzymatic hydrogelation of small molecules, Acc. Chem. Res., 2008, 41, 315-326.

12 S. H. Jung, K. Y. Kim, D. K. Woo, S. S. Lee and J. H. Jung, $\mathrm{Tb}^{3+}$-triggered luminescence in a supramolecular gel and its use as a fluorescent chemoprobe for proteins containing alanine, Chem. Commun., 2014, 50, 13107-13110.

13 Q. Lin, B. Sun, Q. P. Yang, Y.-P. Fu, X. Zhu, Y. M. Zhang and T. B. Wei, A novel strategy for the design of smart supramolecular gels: controlling stimuli-response properties through competitive coordination of two different metal ions, Chem. Commun., 2014, 50, 1066910671.

14 H. Komatsu, S. Matsumoto, S. Tamaru, K. Kaneko, M. Ikeda and I. Hamachi, Supramolecular hydrogel exhibiting four basic logic gate functions to fine-tune substance release, $J$. Am. Chem. Soc., 2009, 131, 5580-5585.

15 G. F. Liu, W. Ji and C. L. Feng, Installing logic gates to multiresponsive supramolecular hydrogel co-assembled from phenylalanine amphiphile and bis(pyridinyl) derivative, Langmuir, 2015, 31, 7122-7128.

16 J. Liu, P. He, J. Yan, X. Fang, J. Peng, K. Liu and Y. Fang, An organometallic supergelator with multiple-stimulus responsive properties, Adv. Mater., 2008, 20, 2508-2511.

17 S. Saha, J. Bachl, T. Kundu, D. D. Diaz and R. Banerjee, Amino acid-based multiresponsive low-molecular weight metallohydrogels with load-bearing and rapid self-healing abilities, Chem. Commun., 2014, 50, 3004-3006.

18 E. Gomar-Nadal, J. Veciana, C. Rovira and D. B. Amabilino, Chiral teleinduction in the formation of a macromolecular multistate chiroptical redox switch, Adv. Mater., 2005, 17, 2095-2098.

19 C. Wan, Q. Chen, F. Sun, D. Zhang, G. Zhang, Y. Huang, R. Zhao and D. Zhu, Multistimuli responsive organogels based on a new gelator featuring tetrathiafulvalene and azobenzene groups: reversible tuning of the gel-sol transition by redox reactions and light irradiation, J. Am. Chem. Soc., 2010, 132, 3092-3096.

20 Y. Jiang, F. Zeng, R. Gong, Z. Guo, C. F. Chen and X. Wan, A multi-stimuli responsive organogel based on a tetrapeptidedithienylcyclopentene conjugate, Soft Matter, 2013, 9, 75387544.

21 R. Afrasiabi and H. B. Kraatz, Rational design and application of a redox-active, photoresponsive, discrete metallogelator, Chem.-Eur. J., 2015, 21, 7695-7700.

22 S. Bhattacharjee and S. Bhattacharya, Pyridylenevinylene based $\mathrm{Cu}^{2+}$-specific, injectable metallo (hydro) gel: thixotropy and nanoscale metal-organic particles, Chem. Commun., 2014, 50, 11690-11693.
23 B. Adhikari, A. J. Lough, B Barker, A. Shah, C. Xiang and H. B. Kraatz, Bis-amino acid derivatives of 1,1'ferrocenedicarboxylic acid: structural, electrochemical, and metal ion binding studies, Organometallics, 2014, 33, 48734887.

24 R. Afrasiabi and H. B. Kraatz, Rational design and application of a redox-active, photoresponsive, discrete metallogelator, Chem.-Eur. J., 2015, 21, 7695-7700.

25 C. W. Liu, M. Su, X. L. Li, T. Xue, N. Liu, J. Yin, Y. Y. Zhu and Z. Q. Wu, Multi-stimuli-responsive chiral organogels based on peptide derivatives, Soft matter, 2015, 11, 5727-5737.

26 G. F. Liu, W. Ji, W. L. Wang and C. L. Feng, Multiresponsive hydrogel coassembled from phenylalanine and azobenzene derivatives as 3D scaffolds for photoguiding cell adhesion and release, ACS Appl. Mater. Interfaces, 2014, 7, 301-307.

27 M. Orojloo and S. Amani, Synthesis and studies of selective chemosensor for naked-eye detection of anions and cations based on a new Schiff-base derivative, Talanta, 2016, 159, 292-299.

28 T. Simon, M. Shellaiah, V. Srinivasadesikan, C. C. Lin, F. H. Ko, K. W. Sun and M. C. Lin, A simple pyrene based AIEE active schiff base probe for selective naked eye and fluorescence off-on detection of trivalent cations with live cell application, Sens. Actuators, B, 2016, 231, 18-29.

29 A. R. Chowdhury, B. G. Roy, S. Jana, T. Weyhermuller and P. Banerjee, A simple cleft shaped hydrazine-functionalized colorimetric new Schiff base chemoreceptor for selective detection of $\mathrm{F}^{-}$in organic solvent through PET signaling: development of a chemoreceptor based sensor kit for detection of fluoride, Sens. Actuators, B, 2017, 241, 706-715.

30 M. Fujita, O. C. Lightbody, M. J. Ferguson, R. McDonald and J. M. Stryker, Quasi-planar homopolymetallic and heteropolymetallic coordination arrays surface-like molecular clusters of magnesium and aluminum, J. Am. Chem. Soc., 2009, 131, 4568-4569.

31 C. Kar, S. Samanta, S. Goswami, A. Ramesh and G. Das, A single probe to sense Al (III) colorimetrically and Cd (II) by turn-on fluorescence in physiological conditions and live cells, corroborated by X-ray crystallographic and theoretical studies, Dalton Trans., 2015, 44, 4123-4132.

32 L. Xu, S. Han, Y. Hu, J. J. Dynes and L. Zhang, Rhodamine Bbased ordered mesoporous organosilicas for the selective detection and adsorption of $\mathrm{Al}$ (III), New J. Chem., 2016, 40, 6752-6761.

33 X. Liu, Q. Lin, T. B. Wei and Y. M. Zhang, A highly selective colorimetric chemosensor for detection of nickel ions in aqueous solution, New J. Chem., 2014, 38, 1418-1423.

34 S. Tao, Y. Wei, C. Wang, Z. Wang, P. Fan, D. Shi, B. Ding and J. Qiu, A quinoline-functionalized amphiphilic fluorogenic probe for specific detection of trivalent cations, RSC Adv., 2014, 4, 46955-46961.

35 A. Dhara, A. Jana, N. Guchhait, P. Ghosh and S. K. Kar, Rhodamine-based molecular clips for highly selective recognition of $\mathrm{Al}^{3+}$ ions: synthesis, crystal structure and spectroscopic properties, New J. Chem., 2014, 38, 1627-1634.

36 Z. X. Liu, Y. Sun, Y. Feng, H. Chen, Y.-M. He and Q.-H. Fan, Halogen-bonding for visual chloride ion sensing: a case 
study using supramolecular poly(aryl ether) dendritic organogel systems, Chem. Commun., 2016, 52, 2269-2272.

37 X. Guan, K. Fan, T. Gao, A. Ma, B. Zhang and J. Song, A novel multi-stimuli responsive gelator based on D-gluconic acetal and its potential applications, Chem. Commun., 2016, 52, 962-965.
38 P. Lin, N. X. Zhang, J. J. Li, J. Zhang, J. H. Liu, B. Zhang and J. Song, To gel or not to gel: a prior prediction of gelation in solvent mixtures, Chin. Chem. Lett., 2017, 28, 771-776.

39 N. X. Zhang, P. Lin, J. J. Li, J. H. Liu, B. Zhang and J. Song, The gelation rule of the polyol acetal derivatives in binary solvent mixtures, Chin. Chem. Lett., DOI: 10.1016/ j.cclet.2017.06.005. 